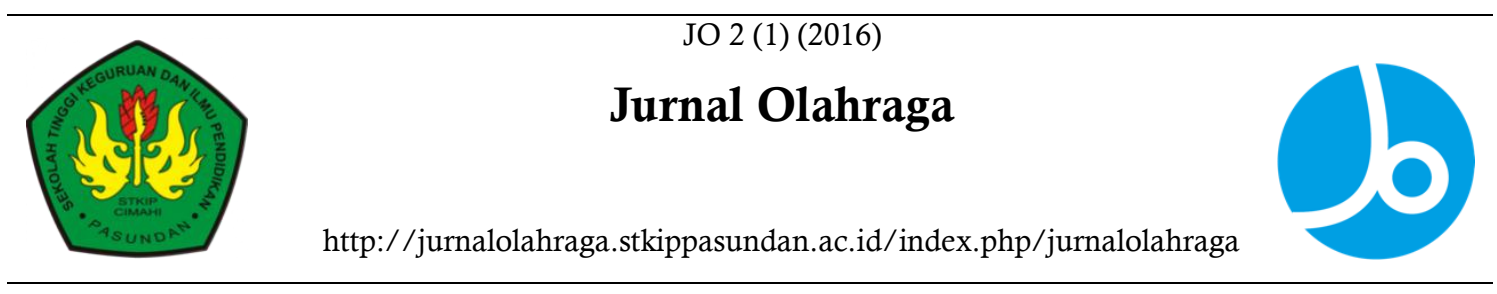

\title{
Keterampilan Dribbling Bola Basket
}

Dedi Kurnia

STKIP Pasundan, Indonesia

\section{Info Artikel}

Sejarah Artikel:

Diterima Januari 2016

Disetujui Maret 2016

Dipublikasikan April 2016

Keywords:

Koordinasi Mata-Tangan,

Kelincahan, Percaya Diri,

Dribbling Bola Basket

\begin{abstract}
Abstrak
Tujuan penelitian ini untuk menentukan hubungan antara kordinasi mata-tangan, kelincahan dan rasa percaya diri dengan keterampilan dribbling bola basket. Metode penelitian yang digunakan dalam penelitian ini adalah korelasional. Objek penelitian ini adalah seluruh siswa SMA/SMK Puragabaya yang mengikuti ekstrakurikuler bola basket. Variabel bebas adalah kordinasi matatangan (X1), kelincahan(X2), dan rasa percaya diri (X3). Sedangkan variabel terikatnya adalah keterampilan dribbling bola basket(Y). Hasil penelitian ini adalah: Pertama, terdapat korelasi positif dan signifikan antara X1danY dengan koefisien korelasi sebesar 0.76 dan indeks determinasi sebesar58.0\%. Kedua, terdapat korelasi yang positif dan signifikan antara $\mathrm{X} 2$ danY dengan koefisien korelasi sebesar 0.81 dan indeks determinasi sebesar $65.0 \%$. Ketiga, terdapat korelasi positif dan signifikan antaraX3 danY dengan koefisien korelasi sebesar 0.73 dan indeks determinasi sebesar $53.0 \%$. Keempat, terdapat hubungan yang positif dan signifikan antara X1, $\mathrm{X} 2$ dan X3denganY,dengan koefisien korelasi sebesar 0.83 dan indeks determinasi sebesar68.4\%. Dapat disimpulkan bahwa keterampilan dribbling bola basket dapat ditingkatkan dengan melatih koordinasi mata-tangan, kelincahan dan rasa percaya diri.
\end{abstract}

\begin{abstract}
The purpose of this study is to determine the relationship between eye-hand coordination, agility and self-confidence with basketball dribbling skills. The research method used in this study is correlational. The object of this research is all Puragabaya / SMA / SMK students who take basketball extracurricular activities. The independent variable is eye-hand coordination (X1), agility (X2), and self-confidence (X3). While the dependent variable is the basketball dribbling skill (Y). The results of this study are: First, there is a positive and significant correlation between $X 1$ and $Y$ with a correlation coefficient of 0.76 and a determination index of $58.0 \%$. Second, there is a positive and significant correlation between $X 2$ and $Y$ with a correlation coefficient of 0.81 and $a$
\end{abstract}


determination index of $65.0 \%$. Third, there is a positive and significant correlation between $X 3$ and $Y$ with a correlation coefficient of 0.73 and a determination index of 53.0\%. Fourth, there is a positive and significant relationship between X1, X2 and $X 3$ with $Y$, with a correlation coefficient of 0.83 and a determination index of $68.4 \%$. It can be concluded that basketball dribbling skills can be improved by practicing eye-hand coordination, agility and self-confidence.

(C) 2016 Dedi Kurnia

Under the license CC BY-SA 4.0

$凶$ Alamat korespondensi:

ISSN 2442-9961 (cetak)

E-mail:wesaidyeah@gmail.com

\section{PENDAHULUAN}

Olahraga mempunyai banyak cabang dalam pelaksanaannya salah satunya adalah bola basket, pada zaman sekarang bola basket semakin diketahui dan dimainkan oleh kebanyakan masyarakat, permainan bola basket juga dapat dimainkan oleh pria maupun wanita dari segala usia dan ukuran tubuh, olahraga bola basket merupakan cabang olahraga yang populer diseluruh dunia.

Olahraga ini telah banyak digemari orang-orang baik di Indonesia maupun negara-negara lain di dunia, mulai dari usia anak-anak, remaja hingga dewasa. Permainan bola basket merupakan permainan yang dimainkan oleh dua regu yang masingmasing regu terdiri dari 5 orang pemain. Tiap regu berusaha memasukkan bola ke dalam keranjang lawan dan mencegah regu lawan memasukkan bola atau membuat angka/skor.

Penguasaan terhadap keterampilan teknik dasar bukanlah hal yang mudah,karena permainan bola basket menuntut keterampilan yang kompleks, artinyagerakannya terdiri dari gabungan unsur-unsur gerak yang terkoordinasi rapisehingga pemain dapat bermain dengan baik. Menurut Miller dan Coffeyteknik dasar yang harus dikuasai dan di $\neg$ perhatikan dalam permainan bola basket, diantaranya : 1)ball handling, 2) dribble, 3) footwork, 4) shoot, 5) passing.

Salah satu teknik dasar yang memerlukan pembinaan, pelatihan dan pengajaran yang amat penting adalah teknik dribblingkarena teknik ini adalah salah satu teknik yang banyak menarik fokus perhatian serta dijadikan langkah awal untuk menjalankan pertandingan. Kemampuan untuk dribbling bola basket dan menangani bola dalam berbagai situasi adalah keterampilan penting bagi pemain muda untuk berkembang. Bahkan, dribbling adalah keterampilan pertama bahwa pemain harus bekerja untuk mengembangkan.

Dribbling adalah suatu usaha membawa bola atau menghidupkan permainan dalam bola basket. Caranya yaitu dengan memantul-mantulkan bola ke lantai dengan satu tangan. Saat bola bergerak ke atas telapak tangan menempel pada bola dan mengikuti arah bola. Tekanlah bola saat mencapai titik tertinggi ke arah bawah dengan sedikit meluruskan siku tangan diikuti dengan kelenturan pergelangan tangan. Teknik ini terbagi kedalam dua jenis, yaitu dribbling bola basket rendah dan dribbling bola basket tinggi, dribbling bola basket 
rendah bertujuan untuk melindungi bola dari jangkauan lawan.

Rahmi (2014) menuturkan Dribbling bola basket tinggi dilakukan untuk mengadakan serangan yang cepat ke daerah pertahanan lawan.

Dalam dribbling dibutuhkan koordinasi yang baik antara mata untuk melihat arah dan tangan untuk mengendalikan bola, sehingga bola bisa terarah dengan baik dan tepat, dalam dribbling koordinasi antara mata dan tangan berperan dalam permainan bola basket agar dalam dribbling pemain sudah mempuyai kepekaan terhadap bola basket itu sendiri sehingga tidak harus selalu melihat bola.pemain yang me $\neg$ miliki kemampuan dalam mengkoordinasi yang baik antara mata dan tangan, akan menghasilkan dribbling yang lebih tepat pada sasaran dan pemain akan semakin mudah dalam mengantisipasi bola.

Selain hal itu dalam dribbling perlu adanya komponen agility atau kelincahan dimana pergerakan cepat pemain saat mendribbling bola sangat diperlukan saat mereka menyerang maupun saat dalam keadaan dijaga oleh lawan, karena berhasil tidaknya seorang pemain mendribbling bola ditopang oleh komponen kelincahan yang bisa membuat pergerakan semakin sulit ditebak oleh lawan. Dalam komponenkomponen dribbling masih ada yang perlu diperhatikan dalam keberhasilan melakukan gerakan dribbling bola basket, yaitu rasa percaya diri.

Menurut Oliver (2009) setiap tim memerlukan pemain yang memiliki kepercayaan diri dan keterampilan untuk mendribble bola menghadapi jenis pertahanan apapun.

Menurut McGee (2007) komponen dasar untuk gerakan dribbling diantaranya adalah :Penempatan tubuh, Melindungi bola, Menjaga pandangan agar tetap ke depan, Menggunakan tangan, Langkah kaki yang tepat. Dribbling diarahkandandikendalikan olehtangan, matatidakpada bolatetapi padakeranjangdanrekan tim.

Usahakan agar posisi tubuh rileks dan seimbang. Bola dilemparkan ke lantai, jangan dipukul atau dibantingkan, tetapi usahakan untuk menjatuhkan bola' tadi. Kalau anak sudah bisa menguasai teknik dribbling ini dengan baik, kemudian ajarlah dia untuk melihat kemana ia akan pergi.

Situasi saat pemain memegang bola dan belum melakukan dribbling sering disebut bola hidup. Pemain harus belajar melakukan dribbling tanpa melihat bola, biasakan mata agar melihat keseluruhan/sekeliling lapangan. Kosasih (2008) kembali menuturkan, sebelum dribbling dilakukan, pemain harus tahu apa tujuannya melakukan dribbling, tujuan yang umum biasanya adalah melewati defender dan mencetak skor. Tapi tujuan dari dribbling bisa lebih spesifik dari pada itu.

Kebiasaan buruk pemain melakukan dribble ditempat sekali atau dua kali adalah kebiasaan buruk, penggunaan dribble harus mempunyai tujuan yang jelas, paling tidak dribble mampu merubah arah pergerakan defender. Koordinasi sangat penting dimiliki oleh seorang atlet untuk menunjang penampilan (performance) yang baik. Bagi pemain bola basket yang senantiasa berada dalam lingkungan yang asing seperti perubahan lapangan misalnya, tingkat koordinasi ini sangat diperlukan untuk melakukan suatu gerakan secara mulus, tepat (precise) dan efisien.

Kelincahan merupakan salah satu komponen fisik yang sangat diperlukan pada semua aktifitas yang membutuhkan kecepatan perubahan posisi tubuh dan bagianbagiannya. Kelincahan sering dikaitkan dengan fleksibilitas meskipun itu hal yang berbeda. Dalam olahraga percaya diri sudah pasti menjadi salah satu faktor penentu suksesnya seorang atlet, percaya diri adalah 
elemen terpenting dalam pertandingan. Sebaliknya kehilangan kepercayaan diri akan Iangsung berakibat buruk pada prestasi. Sudibyo (2002) menegaskan sebagai berikut :

Percaya diri atau "self-confidence" merupakan modal utama seorang atlet untuk dapat maju, karena pencapaian prestasi yang tinggi dan pemecahan rekor atlet itu sendiri harus dimulai dengan percaya bahwa ia dapat dan sanggup melampaui prestasi yang pernah dicapainya.

Masalah kurang atau hilangnya rasa percaya diri terhadap terhadap kemempuan diri sendiri akan mengakibatkan atlet tampil dibawah kemampuannya. Percaya diri merupakan keyakinan dalam jiwa bahwa kesulitan haruslah dihadapi dengan berbuat sesuatu. Atlet dengan percaya diri positif akan menafsirkan kesulitan dan perasaan sedih sesaat menjelang suatu pertandingan sebagai suatu kegembiraan yang berarti bahwa mereka akan tampil dengan baik. Mereka menafsirkan emosinya dengan cara yang positif dan meningkatkan diri. Sebaliknya percaya diri kurang, tingkat kebangkitan yang sama ditafsirkan sebagai ketakutan. Berdasarkan uraian latar belakang yang telah di dikemukakan di atas, maka tujuan pelaksanaan penelitian ini adalah: ingin mengetahui hubungan antara koordinasi mata-tangan, kelincahan, dan percaya diri dengan keterampilan dribbling bola basket.

\section{METODE}

Metode penelitian yang digunakan adalah metode korelasi. Korelasi yang diteliti adalah korelasi multi variabel karena terdapat empat variabel yang berhubungan. hubungan antara variabel bebas $\mathrm{X} 1$ yaitu kordinasi mata-tangan, X2 yaitu kelincahan, dan X3 yaitu percaya diri dengan variabel $(\mathrm{Y})$ yaitu keterampilan dribbling bola basket, dengan desain penelitiannya dapat digambarkan sebagai berikut:

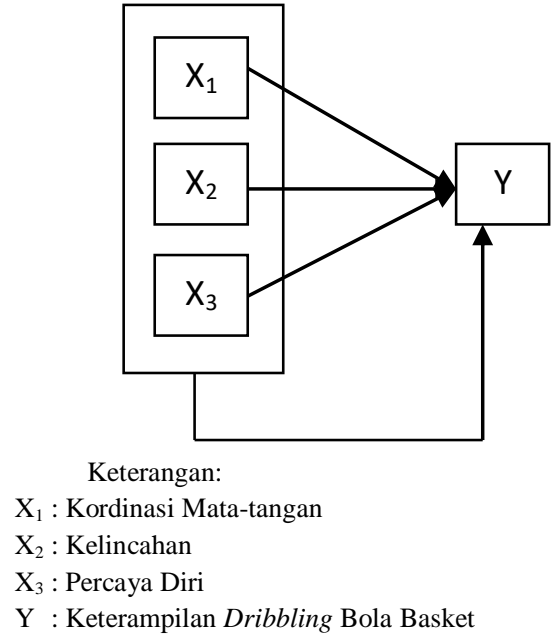

\section{Gambar 1. Desain Penelitian}

Populasi dalam penelitian ini adalah seluruh anggota ekstrakurikuler bola basket SMA/SMK Puragabaya 2015 yang mengikuti latihan rutin.

Sampel penelitiannya adalah anggota ekstrakurikuler bola basket SMA/SMK Puragabaya 2015. Sampel yang digunakan dalam penelitian ini berjumlah 32 dari populasi keseluruhan (total sampling). Berdasarkan rancangan penelitian di atas maka terdapat empat data yang harus dikumpulkan yaitu: 1) Data tentang keterampilan dribbling bola basket, 2) Data tentang koordinasi mata-tangan, 3) Data tentang kelincahan dengan menggunakan tes, dan 4) Data tentang percaya diri, dengan menggunakan kuisioner.

Pengumpulan data menggunakan instrumen tes penelitian yang telah ditentukan oleh peneliti, dan telah di uji coba terlebih dahulu untuk dapat diketahui tingkat validitas dan reliabilitas tesnya. Berdasarkan hasil uji coba instrument diketahui:

1. Untuk mengukur keterampilan dribbling bola basket maka digunakan tes keterampilan dribbling bola basket dari buku Tes dan Pengukuran Keolahragaan 
(Nurhasan, 2011: 243). Berikut adalah gambar tes dribbling bola basket :

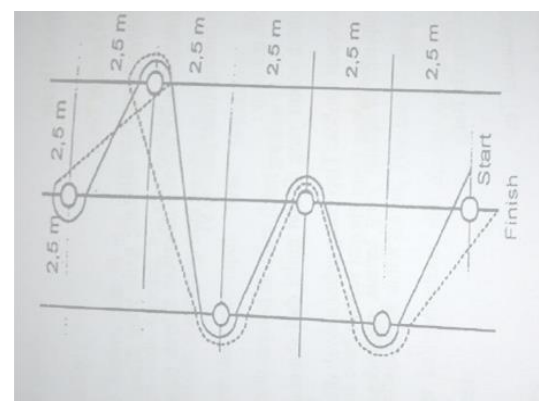

\section{Gambar 2. Tes Dribbling Bola Basket}

2. Untuk mengukur koordinasi mata-tangan digunakan tes lempar tangkap bola yang telah dimodifikasi oleh peneliti

3. Untuk mengukur kelincahan maka digunakan tes Zig-Zug Run dari buku Tes dan Pengukuran Olahraga (Widyastuti, 2011: 126). Berikut adalah gambar tes Zig-Zug Run:

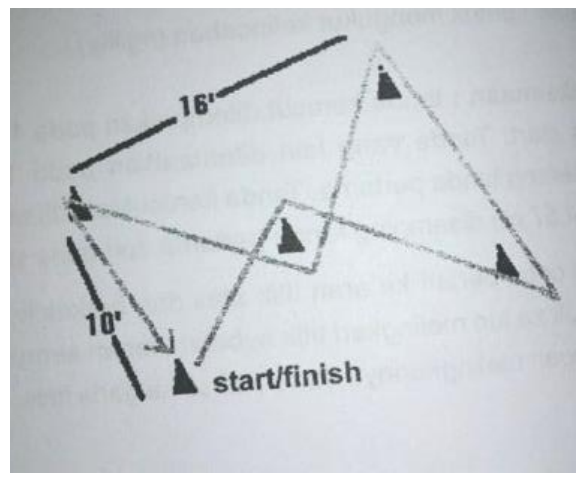

\section{Gambar 3. Tes Zig-Zug Run}

4. Untuk percaya diri menggunakan angket, dengan menggunakan skala Likert.

\section{HASIL DAN PEMBAHASAN}

Hasil data penelitian dimulai dari setiap variabel disajikan dan disusun berdasarkan skor tertinggi, skor terendah, rata-rata $(\bar{X})$ mean dan standar deviasi (SD). Selanjutanya disajikan dalam bentuk tabel distribusi frekuensi dan diagram batang berdasarkan hasil penelitian yang sudah diperoleh.

Tabel 1. Deskripsi data Variabel Koordinasi Mata Tangan, Kelincahan, Percaya Diri dan keterampilan Dribbling

\begin{tabular}{|c|c|c|c|c|}
\hline Variabel & Min & Maks & Mean & SD \\
\hline $\begin{array}{c}\text { Koordinasi Mata Tangan } \\
(\mathrm{X} 1)\end{array}$ & 6,50 & 9,50 & 7,92 & 0,81 \\
\hline $\begin{array}{c}\text { Koordinasi Kelincahan } \\
(\mathrm{X} 2)\end{array}$ & 6,60 & 8,15 & 7,30 & 0,34 \\
\hline Percaya Diri (X3) & 122,0 & 151,0 & 133,09 & 8,70 \\
\hline DribblingBola Basket (Y) & 10,0 & 17,0 & 13,48 & 1,94 \\
\hline
\end{tabular}

\section{Koordinasi Mata-Tangan}

Berdasarkan tabel diatas, diperoleh data hasil penelitian yang terkumpul dari hasil tes Koordinasi Mata tangan (X1) dengan skor terendah 6,50, skor tertinggi 9,5, skor rata-rata 7,92, standar deviasi 0,81 .

Tabel 2. Distribusi frekuensi dari hasil tes Koordinasi Mata Tangan (X1)

\begin{tabular}{|c|c|c|c|}
\hline No & Interval & $\begin{array}{c}\text { FrekuensiAbsolut } \\
\text { Data (fd) }\end{array}$ & $\begin{array}{c}\text { Frekuensi Relatif } \\
\text { Data (\%) }\end{array}$ \\
\hline 1 & $6,5-6,70$ & 6 & 18,8 \\
\hline 2 & $7,01-7,5$ & 11 & 34,4 \\
\hline 3 & $7,51-8,0$ & 2 & 6,3 \\
\hline 4 & $8,01-8,5$ & 8 & 25,0 \\
\hline 5 & $8,51-9,0$ & 3 & 9,4 \\
\hline 6 & $9,01-9,50$ & 2 & 6,3 \\
\hline \multicolumn{2}{|c|}{ Jumlah } & 32 & 100,0 \\
\hline
\end{tabular}

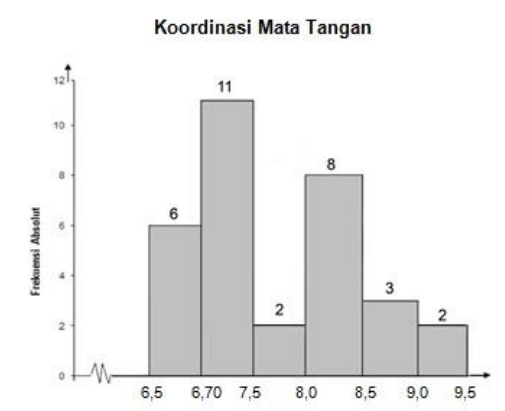

Gambar 4. Diagram Histogram Distribusi frekuensi variable Koordinasi Mata-tangan 


\section{Kelincahan}

Berdasarkan tabel diatas, diperoleh data hasil penelitian yang terkumpul dari hasil tes Kelincahan (X2) dengan skor terendah 6,60, skor tertinggi 8,15, skor ratarata 7,30, standar deviasi 0,34.

Tabel 3. Distribusi frekuensi dari hasil tes Kelincahan (X2)

\begin{tabular}{|c|c|c|c|}
\hline No & Interval & $\begin{array}{c}\text { Frekuensi Absolut } \\
\text { Data (fd) }\end{array}$ & $\begin{array}{c}\text { Frekuensi } \\
\text { Relatif Data (\%) }\end{array}$ \\
\hline 1 & $6,60-6,86$ & 2 & 6,3 \\
\hline 2 & $6,87-7,11$ & 6 & 18,8 \\
\hline 3 & $7,11-7,37$ & 12 & 37,5 \\
\hline 4 & $7,38-7,63$ & 8 & 25,0 \\
\hline 5 & $7,64-7,89$ & 0 & 0,0 \\
\hline 6 & $7,90-8,15$ & 4 & 12,5 \\
\hline \multicolumn{2}{|c|}{ Jumlah } & 32 & 100,0 \\
\hline
\end{tabular}

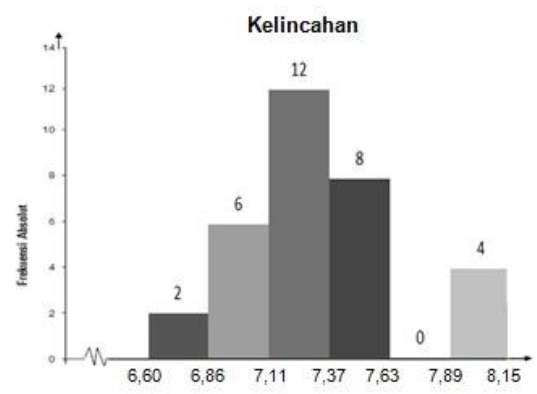

\section{Gambar 5. Diagram Histogram Distribusi} frekuensi variable Kelincahan

\section{Percaya diri}

Berdasarkan tabel diatas, diperoleh data hasil penelitian yang terkumpul dari hasil tes Percaya Diri (X3) dengan skor terendah 122,0, skor tertinggi 151,0, skor rata-rata 133,09, standar deviasi 8,70.

Tabel 4. Distribusi frekuensi dari hasil tes Percaya Diri (X3)

\begin{tabular}{|c|c|c|c|}
\hline No & Interval & $\begin{array}{c}\text { Frekuensi } \\
\text { Absolut Data (fd) }\end{array}$ & $\begin{array}{c}\text { Frekuensi } \\
\text { Relatif Data (\%) }\end{array}$ \\
\hline 1 & $122,0-126,83$ & 10 & 31,3 \\
\hline 2 & $126,83-131,67$ & 6 & 18,8 \\
\hline 3 & $131,68-136,50$ & 3 & 9,4 \\
\hline 4 & $136,51-141,33$ & 6 & 18,8 \\
\hline 5 & $121,34-146,17$ & 5 & 15,6 \\
\hline
\end{tabular}

\begin{tabular}{|c|c|c|c|}
6 & $146,18-151,0$ & 2 & 6,3 \\
\hline Jumlah & 32 & 100,0 \\
\hline
\end{tabular}

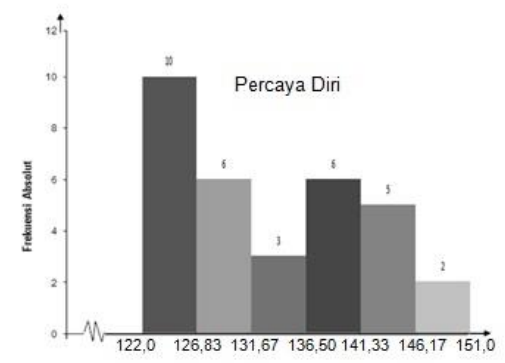

Gambar 6. Diagram Batang Distribusi frekuensi variable percaya diri

4. Dribbling Bola Basket

Berdasarkan tabel diatas, diperoleh data hasil penelitian yang terkumpul dari hasil tes Dribbling Bola Basket (Y) dengan skor terendah 10,0, skor tertinggi 17,0, skor rata-rata 13,48, standar deviasi 1,94.

Tabel 5. Distribusi frekuensi dari hasil tes Tes Dribbling Bola Basket (Y)

\begin{tabular}{|c|c|c|c|}
\hline No & Interval & $\begin{array}{c}\text { Frekuensi Absolut } \\
\text { Data (fd) }\end{array}$ & $\begin{array}{c}\text { Frekuensi } \\
\text { Relatif Data }(\%)\end{array}$ \\
\hline 1 & $10,0-11,17$ & 6 & 18,8 \\
\hline 2 & $11,18-12,33$ & 3 & 9,4 \\
\hline 3 & $12,34-13,50$ & 7 & 21,9 \\
\hline 4 & $13,51-14,67$ & 4 & 12,5 \\
\hline 5 & $14,78-15,83$ & 10 & 31,3 \\
\hline 6 & $15,84-17,0$ & 2 & 6,3 \\
\hline \multicolumn{2}{|r|}{ Jumlah } & 32 & 100,0 \\
\hline
\end{tabular}

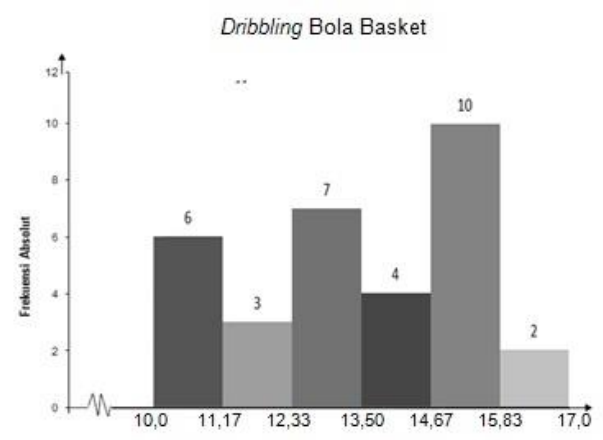

\section{Gambar 7. Diagram Histogram Distribusi frekuensi variable Dribbling Bola Basket}

Selanjutnya, proses pengolahan data untuk pengujian hipotesis meliputi uji korelasi, uji signifikansi dan indeks 
determinasi. Dari hasil pengolahan data diperoleh hasil sebagai berikut :

1. Korelasi variabel koordinasi mata tangan (X1) dengan keterampilan dribbling bola basket (Y) sebesar 0,76. Hasil t hitung uji signifikansi variabel koordinasi mata tangan (X1) dengan keterampilan dribbling bola basket (Y) sebesar 6,397.Dari hasil uji indeks determinasi diperoleh hubungan koordinasi mata tangan (X1) dengan keterampilan dribbling bola basket (Y) sebesar 58,0\%.

2. Korelasi variabel kelincahan (X2) dengan keterampilan dribbling bola basket (Y) sebesar 0,81. Hasil t hitung uji signifikansi variabel kelincahan (X2) dengan keterampilan dribbling bola basket (Y) sebesar 7,53. Dari hasil uji indeks determinasi diperoleh hubungan kelincahan (X2) dengan keterampilan dribbling bola basket (Y) sebesar 65,0\%.

3. Korelasi variabel percaya diri (X3) dengan keterampilan dribbling bola basket (Y) sebesar 0,73. Hasil t hitung uji signifikansi variabel percaya diri (X3) dengan keterampilan dribbling bola basket (Y) sebesar 5,83. Dari hasil uji indeks determinasi diperoleh hubungan (X3) dengan keterampilan dribbling bola basket (Y) sebesar 53,0\%.

4. Korelasi ganda $\left(\mathrm{r}_{\mathrm{X} 1 \times 2 \times 3} \mathrm{y}\right)$ dari tiga variabel bebas (koordinasi mata tangan, kelincahan,dan percaya diri) dengan satu variabel terikat (keterampilan dribbling bola basket) sebesar 0,83 . Hasil F hitung uji signifikansi variabel koordinasi mata tangan, kelincahan,dan percaya diri $(\mathrm{X} 1, \mathrm{X} 2, \mathrm{X} 3)$ dengan keterampilan dribbling bola basket (Y) sebesar 20,18. Dari hasil uji indeks determinasi diperoleh hubungan koordinasi mata tangan, kelincahan,dan percaya diri $(\mathrm{X} 1, \mathrm{X} 2, \mathrm{X} 3)$ dengan keterampilan dribbling bola basket (Y) sebesar 68,4\% .

\section{KESIMPULAN}

Dari hasil pengolahan data maka dapat ditarik kesimpulan :

1. Terdapat hubungan positif dan signifikan antara koordinasi mata-tangan dengan keterampilan dribbling bola basket.

2. Terdapat hubungan positif dan signifikan antara kelincahan dengan keterampilan dribbling bola basket.

3. Terdapat hubungan positif dan signifikan antara percaya diri dengan keterampilan dribbling bola basket.

4. Terdapat hubungan positif dan signifikan antara koordinasi mata-tangan, kelincahan, dan percaya diri secara bersamasama dengan keterampilan dribbling bola basket.

Hasil penelitian ini memberikan implikasi bahwa salah satu upaya untuk meningkatkan keterampilan dribbling bola basket dalam permainan bola basket adalah dengan meningkatkan koordinasi matatangan, kelincahan, dan percaya diri. Tetapi tetap harus diingat bahwa masih ada faktor lain yang berpengaruh terhadap keterampilan dribbling bola basket dalam permainan futsal, sehingga perlu adanya penelitian lebih lanjut lagi.

\section{DAFTAR PUSTAKA}

Amber,Vick. (2013).Petunjuk Untuk Pelatih

Dan Pemain Bola Basket. Bandung: Pionir Jaya

Barth \& Boesing. (2010). Training Basketball. UK : Meyer \& Meyer Sport Kosasih, Danny.(2008) Fundamental Basketball. Semarang: Karangturi Media McGee, Kathy.(2007). Coaching Basketball Technical And Tactical Skills. USA : Human Kinetics

Miller \& Coffey. (2009). Winning basketball for Girls. New York : Chelsea House

Nurhasan. (2011). Tes dan Pengukuran Keolahragaan. Bandung : STKIP Pasundan 
Oliver ,Jon. (2009). Dasar-Dasar Bola Basket. Bandung : Pakar Raya

Rahmi, Mikanda. (2014). Buku Super Olahraga Lengkap. Jakarta : Dunia Cerdas

Setyobroto, Sudibyo. (2002). Psikologi Plahraga. Jakarta: Universitas Negri Jakarta.
Taylor,Gerard.

(2005).Capoeira

Conditioning. California : Blue Snakes Books

Widiastuti. (2011). Tes dan Pengukuran Olahraga. Jakarta : PT. Bumi Timur Jaya. 